\title{
Optimizing Feed Withdrawal in Broiler Effect of Feed Withdrawal Timing on Broiler Carcass Yield in Tropics
}

\author{
Hamidu, J.A, Kyeiwaa, V, Bobie-Ansah, D, Brown, C.A., Atuahene, C.C. Adomako, K \\ ${ }^{1}$ Department of Animal Science, ${ }^{1}$ Kwame Nkrumah University of Science and Technology, Kumasi, Ghana
}

\begin{abstract}
Food and for that matter poultry meat contamination has become a major concern to poultry producers, processors and consumers. The objectives of this study was to determine the optimum feed withdrawal time on broiler yield and provide basis formajor welfare problems in broiler destined for slaughter and processing. Two experiments were conducted. Experiment 1 was an on-farm data collection system based on typical feed withdrawal time practicedby a commercial farm on carcass yield. In experiment 2, Hubbard commercial day old chicks $(n=200)$ were weighed and reared under anad-libitumfeeding and water condition for 56 days. At 56 days, broilers were randomly allocated to 5 feed withdrawal treatments $(0,4,8,12$ and 16 hours) prior to slaughter.Parameters measured were the average feed intake and initial body weight, final live body weight, intestinal and crop weight, dressed weight and feed conversion ratio. All data were analyzed using the Generalized Linear Model ofSAS (Proc. GLM procedure)and lsmeans separated by SNK at $P<0.05$. In experiment 1, a fixed 16 hour feed withdrawal period resulted in $267.5 \mathrm{~g}$ live weight loss between before and after feed withdrawal. In experiment 2, the initial body weight and the feed intake was the same for all birds reared.The final live body weight, intestines and crop weight reduced significantly as the feed withdrawal time increased. The dressed weight of the 8,12 and 16 hours was significantly $(\mathrm{P}<0.0001)$ lower than 0 and 4 hour withdrawal time. There was increased intestinal sloughing in 12 and 16 hours withdrawal treatment, indicating increasing poor welfare implications on the birds. Increasing length of feed withdrawal increased feed conversion ratio which was due heavily to live weight reduction as withdrawal time increased. While feed withdrawal has it benefits, the physical reduction in body weight, dressed weight and intestinal integrity pose a welfare danger to the birds in longer hours.
\end{abstract}

Key Words: Broilers, feed withdrawal time, processing, weight loss, meat yield

\section{INTRODUCTION}

Food and for that matter poultry meat contamination at slaughter has attracted concern of producers, processors and consumers in the current decade (Javadi and Safermashaei 2011).In other words, feed and sometimes water withdrawal before slaughter while being an efficient and commonly employed method in an attempt to reduce contamination through gash from the gastrointestinal tract onto the carcasses during processing can also affect meat yield (Duke etal., 1997; Baracho et al., 2006; Nunes 2005).In 2008 a listeria breakout and contamination in Maple Leaf Plant in Ontario created a Public panic in Canada (Mansel 2008). Up till today it has not been discovered how the listeria species that caused many to fall sick in Canada appeared in the Maple Leaf Plant resulting in meat contamination. In addition, it is not clear where in the entire broiler production chain it was introduced. However, one of the possible points of entry could be through intestinal gash out during processing. This could be due to residual digest a still present in the intestine. Depending on the feed withdrawal time prior to slaughter and processing in the event of insufficient withdrawal time tension could build up in the guts that could burst during processing spilling infected gut content on the meat.

In broiler production, contamination can increase production costs and this has been a major challenge to processors (Savage 1998). When investigating into some of the possible methods of reducing contamination, it is important to determine the type of material contaminating the carcasses during processing. Most carcass contamination may result from sources such as feed, feces, watery gut contents, litter, broken down intestinal lining, bile, and cecal contents (Savage 1998).During transportation of live broilers from farms to processing plant, contamination may result from the nature of transport crates which is a significant source of Salmonella on carcasses after processing (Rigby and Petit1981). There is therefore a need to determine the sources and the types of contamination that may render meat unwholesome in order to develop alternative standardized operating procedures to reduce contamination

${ }^{1}$ Corresponding Author: jahamidu@gmail.com 
and reduce impact on human health especially in developing countries like Ghana. Generally, an optimal feed withdrawal time is required to lower the occurrence of carcass contamination and reduce carcass yield losses (Wabeck 1972; Orlic et al., 2007). This could lead to improve product safety. In addition, the chances of meat being contaminated and downgraded will decrease(Northcutt etal., 2003). With proper feed withdrawal time there is a reduction in carcass condemnations during processing. Feed withdrawal time is also affected by certain factors thatcould impact the digestive tract clearance time. These include: health status of the broiler chicken, composition of feed or feeding program, lighting program me, extremes of environmental temperature and excitement caused by catching and crating (Savage 1998; Buhretal., 1998; Nunes 2005; Northcutt 2001). The feed withdrawal time is also affected by the type of bird and method used during evisceration whether it is done mechanically or by hand and the type of equipment used (May etal., 1989).The objectives of this research was to determine the optimum feed withdrawal time on broiler in commercial operation in Ghana as well as determine the effects of different feed withdrawal times on broiler carcass yield.

\section{MAterials ANd MethodS}

\section{Experiment 1}

\subsection{Location and Duration of Experiment}

The first experiment was an on-farm feed withdrawal trial involving monitoring of broiler growth performance at Dark farms and Co. Ltd located at Esaase- Akropong in the Ashanti Region of Ghana.

\subsection{Experimental Birds, Housing and Management}

A total of 4200 commercial day old broilers (Cobb-500) were housed in a $100 \mathrm{~m} \times 10 \mathrm{~m}$ pen which resulted in approximately $0.24 \mathrm{~m}^{2}$ per bird. Wood shavings were provided as bedding material. Birds were brooded for seven days using pot filled charcoal as heat source. Birds were kept under the intensive system of management. Day old chicks were given glucose in solution for two days on arrival. Birds were vaccinated against Newcastle disease on the ninth (9th) and twenty eighth (28th) days. Gumboro vaccine was administered on the sixteenth (16th) day. Feed and water were given ad libitum throughout the study until slaughter where feed was restricted.

\subsubsection{Feeding}

Birds were fed with starter diet for five weeks and changed into finisher. The starter and finisher feed were prepared using concentrate and maize. A tonne of starter feed was prepared by adding seven bags $(350 \mathrm{~kg})$ of concentrate to six hundred and fifty (650) kilograms of ground maize. The concentrate was composed of $43 \%$ crude protein, $4.40 \%$ crude fat, $5.00 \%$ crude fibre, $3.00 \%$ lysine, $1.20 \%$ methionine, $1.80 \%$ methionine+cysteine, $2.5 \%$ calcium, $0.5 \%$ sodium, $1.16 \%$ phosphorus and $2250 \mathrm{Kcal} / \mathrm{kgmetabolizable} \mathrm{energy} \mathrm{(M.E).} \mathrm{Anti-oxidant,} \mathrm{phytase,} \mathrm{mould} \mathrm{inhibitor}$ and vitamins were also added to the concentrate. At day fifty (50), birds were randomly selected and slaughtered after sixteen (16) hours feed withdrawal.

\subsubsection{Transportation and Processing}

At 50 days old, birds were placed in plastic crates, with eight birds in a crate and transported to the processing plant. Birds were individually stunned electrically, killed manually with a knife and exsanguinated while on the processing line.The birds were then transferred into the scalder with water bath set at $50^{\circ} \mathrm{c}$ for scalding and then to the pluckier for plucking of the feathers. From the plucker, the heads and legs were cut by hand after hanging. An opening cut was made at the anal region of each carcass and was eviscerated manually. Lung gun was used to remove the lungs from the broilers. Carcass was washed further, sort by weight and packaged.

\subsubsection{Parameters Measured}

Parameters measured were initial body weight, weight before feed withdrawal, weight after feed withdrawal, weight loss which was deduced by subtracting the weight after feed withdrawal from weight before feed withdrawal, intestinal weight and examination of its integrity and carcass yield. Gizzard contents were also examined. The weight was measured using electronic scale.

Experiment 2

\subsubsection{Location and Duration of Experiment}

The experiment 2 was conducted at the Poultry Section of the Department of Animal Science farm, Kwame Nkrumah University of Science and Technology, Kumasi. The Department of Animal Science is located between 
latitude $06^{\circ} 43^{1} \mathrm{~N}$ and longitude $01^{\circ} 36$ (Hamidu, 2002). The area lies in the forest zone with an average rainfall of $30 \mathrm{~mm}$ and $200 \mathrm{~mm}$ in January and June respectively with an average temperature between $23^{\circ} \mathrm{C}$ minimum and $35^{\circ} \mathrm{C}$ maximum in February and August respectively (Abubakari, 2013). The experiment lasted for 8 weeks.

\subsubsection{Experimental Design and Broiler Management}

Total of 200 commercial day old Hubbard broilers obtained from a commercial hatchery were brooded for three weeks on wood shavings as bedding. Four hundred watt $(100 \mathrm{~W})$ onion light bulbs were used as a heat source. A thermometer was hanged in the brooder house to record the average daily ambient temperature in order to regulate the heat in the brooder house which was made of aluminum siding during day and night hours. The temperature was regulated by opening windows and turning off lights when the brooder house got hotter. Birds were transported from the brooder house to permanent pens on day 26 of rearing. After 56 days of rearing, the birds were randomly allocated to 5 feed withdrawal treatments $(0,4,8,12$ and 16 hours) prior to slaughtering.

\subsubsection{Feeding, Formulation and Medication}

During the first two weeks of the experiment, all the chicks were fed with Sankofa broiler starter mash (starter 1) composed of $22 \% \mathrm{CP}$ and $2800 \mathrm{M} . \mathrm{E}$ (Kcal/kg). Afterwards, another starter feed (starter 2) was formulated with the feed ingredients bought from a commercial feed supplier (Table 1). The starter 2 was also fed for additional two weeks and then changed to finisher diet (Table 1). Starter 2 and the finisher feed were subjected to proximate analysis (Table 1) according to methods recommended by the AOAC International (2003). The M.E. and nitrogen free extract were calculated as shown in equations 1 and 2 (Crampton et al., 1996). Feed and water were given ad libitum throughout the rearing period until slaughter where birds were subjected to five different feed withdrawal treatments. Birds were vaccinated against Gumboro and Newcastle as shown in the medications schedule provided (Table 3).Following each feed withdrawal treatment 5 birds from each of 3 replicate pens were selected and slaughter following Departmental humane standard procedures of slaughtering animals. All birds had access to light and water during the feed withdrawal periods.

Table1. Feed and proximate composition of starter and finisher diets formulated for broilers reared for 8 weeks

\begin{tabular}{|c|c|c|c|}
\hline Ingredients & Starter diet 2 & Finisher diet & \\
\hline Maize (kg) & 112 & 120 & \\
\hline White fish (kg) & 22 & 20 & \\
\hline Soyabean meal (kg) & 28.5 & 30 & \\
\hline Wheat bran (kg) & 33 & 22 & \\
\hline Oyster shell (kg) & 3.6 & 4 & \\
\hline Premix (kg) & 0.5 & 1 & \\
\hline Salt (kg) & 0.2 & 1 & \\
\hline Dicalcium phosphate $(\mathrm{kg})$ & 0.1 & 1 & \\
\hline Lysine (kg) & 0.1 & 1 & \\
\hline Total $(\mathrm{kg})$ & 200 & 200 & \\
\hline \multicolumn{4}{|l|}{ Proximate composition } \\
\hline Crude protein $(\%)$ & 20.8 & 19.5 & \\
\hline Ether extract (\%) & 2.5 & 3 & \\
\hline Crude fibre $(\%)$ & 5 & 2.22 & \\
\hline $\operatorname{Ash}(\%)$ & 7.5 & 8.5 & \\
\hline Moisture (\%) & 9 & 9 & \\
\hline M.E (Kcal/kg) & 2872.5 & 2959.8 & \\
\hline \multicolumn{3}{|c|}{ NFE $(D M)=100-[\%($ crude protein + ether extract + crude fiber + ash + moisture $)]$} & (Eqn.1) \\
\hline \multicolumn{4}{|c|}{$\mathrm{ME}=[(3.5 \times \% \mathrm{CP})+(8.5 \times \% \mathrm{EE})+(3.5 \times \% \mathrm{NFE})] \times 10$} \\
\hline \multicolumn{4}{|c|}{ Table3. Medications schedule for broiler reared for 8 weeks } \\
\hline Medication & \multicolumn{3}{|c|}{ Day of administering medication } \\
\hline Glucose & \multicolumn{3}{|l|}{1} \\
\hline Narcox plus (coccidiostat) & \multicolumn{3}{|l|}{$3,4,5,20,21,32$} \\
\hline HB1 vaccine & \multicolumn{3}{|l|}{9} \\
\hline Pen-strep plus & \multicolumn{3}{|c|}{$11,12,13,18,19,26,27,28$} \\
\hline Gumboro vaccine & \multicolumn{3}{|l|}{16,30} \\
\hline Lasota & \multicolumn{3}{|l|}{23} \\
\hline Vitamin & \multicolumn{3}{|l|}{$26,27,28,32$} \\
\hline
\end{tabular}




\subsubsection{Movement of Birds and Processing}

Birds were caught and sent to the processing unit at the farm. The controlled broilers (zero feed withdrawal) were the first to be slaughtered after taking their live weight, followed by those on feed withdrawal treatments. Birds were individually killed manually by knife and exsanguinated. The birds were then immersed in boiled water at $50^{\circ} \mathrm{C}$ for scalding and their feathers were plucked manually. The heads, necks and legs were separated by cutting them off manually. An opening cut was made at the anal region of each carcass and was eviscerated manually. The eviscerated carcass was weighed together with the legs, gizzard and liver as the dressed weight. Intestines together with crop were also weighed. Carcasses were washed manually after evisceration and packaged.

\subsubsection{Parameters Measured}

Parameters measured include initial chick weight, total feed intake per bird, weight before feed withdrawal, final live body weight after feed withdrawal, weight gain, weight loss, dressed weight, carcass yield (dressing percentage), intestine and crop weight, feed conversion efficiency

\subsubsection{Data Analysis}

All data collected were analysed using the Generalized Linear Model procedure of SAS (SAS Proc GLM) at P < 0.05. The Lsmeans were separated by the Student's-Newman-Keuls test (SNK) (SAS Institute, 2012).

\section{RESULTS AND DISCUSSION}

\section{Experiment 1}

\subsection{On-Farm Broiler Performance During 16 Hours of Feed Withdrawal}

As shown below (Table 2) the average initial weight of birds was 55g. The average final live weight before and after feed withdrawal at 50 days is given in Table 4 . The weight before 16 hours feed withdrawal was higher than after feed withdrawal by a margin of $267.5 \mathrm{~g}$. This live shrink or percentage weight loss following feed withdrawal after 50 days of rearing was $10.47 \%$. Turkyilmaz et al. (2006) reported that broilers after 14 hours of feed withdrawal showed $15.2 \%$ less body weight than the control (0 hours) at 37 days. Also, Zuidhof et al.

Table2. Effects of 16 hours feed withdrawal on live body weight, carcass yield, and intestine weight after 50 days of broiler rearing

\begin{tabular}{|l|c|}
\hline Parameter & 16 hours feed withdrawal \\
\hline Weight before feed withdrawal $(\mathrm{g})$ & $2555.0 \pm 64.62^{\mathrm{a}}$ \\
\hline Weight after feed withdrawal $(\mathrm{g})$ & $2287.5 \pm 64.62^{\mathrm{b}}$ \\
\hline Weight loss $^{1}(\mathrm{~g})$ & 267.5 \\
\hline Dressed weight $(\mathrm{g})$ & 1550 \\
\hline Carcass yield $^{2}(\%)$ & 67.76 \\
\hline Intestine weight $(\mathrm{g})$ & 72 \\
\hline
\end{tabular}

${ }^{a, b}$ Means with different superscript are significantly different $(P=0.0058)$

${ }^{l}$ Difference between weight before and after feed withdrawal

${ }^{2}$ Dressed weight divided by final weight and multiplied by 100

(2004) reported an increase of shrink from $2.1 \%$ to $3.3 \%$ of live body weight after feed withdrawal period for 4 and 16 hours respectively. It has been suggested that while optimum feed withdrawal time must be long enough to allow adequate gastrointestinal tract clearance, it should also be short enough to reduce live shrink(Bilgili 2002). The carcass yield calculated for the 50 days was $67.76 \%$ which is comparable to Summers and Leeson (1979) who recorded $68.5 \% \pm 1.2 \%$ carcass yield for 16 hours but lower compared to results observed by Zuidhofet al.(2004) who recorded $85 \%$ carcass yield for 16 hours. It is not clear if regional difference have an impact on the stress of feed withdrawal length since the study from the later reference was carried out in a temperate country.

\section{Experiment 2}

\subsection{Initial Chick Weight And Feed Intake}

The average initial chick weight of all birds reared was $44 \mathrm{~g}$. Total feed intake for the entire durations of the study was $4.13 \mathrm{~kg}$ per bird. During the feed withdrawal time, there was no death recorded, however, $11 \%$ of mortality occurred during the first 3 weeks of rearing the broilers which was attributed to chick quality. 


\subsection{Live Body Weight}

Effects of feed withdrawal duration on live body weight have been presented in figure 1 below. It was determined that feed withdrawal timing had significant effect on the slaughter weight after 56 days $(\mathrm{P}<0.001)$. On live weight basis, birds were heavier in the control where there was no feed withdrawal compared to all the feed withdrawal treatments $(4,8,12$, and 16 hours). However, the birds on 4 hours feed withdrawal were heavier than those on 12 and 16 hours, but not those on 8 hours. The birds subjected to 8,12 and 16 hours feed withdrawal treatments were not different from each other. This study revealed that long feed withdrawal duration (16 hours) lead to $28.84 \%$ decrease in body weight compared to the control (0 hours). For birds that are sold on live weight basis this will be a significant economic due to long feed withdrawal. Such feed withdrawal losses are usually unintentional especially where birds are held in transportation crates sitting on the road over half or full day before being slaughtered. Turkyilmaz et al. (2006) reported that feed withdrawal program had negative effect on live body weight. They reported that broilers that have been exposed to 14 hours feed withdrawal showed $15.2 \%$ less body weight than the control (0 hour) at 37 days. In another study progressive live weight loss was observed when feed withdrawal time increased beyond 16 hours (Lyon et al., 1991).

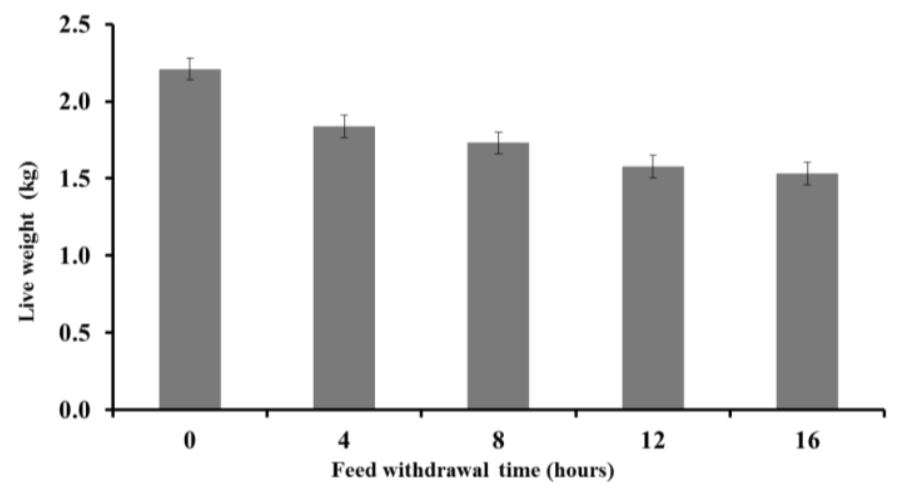

Fig1. Effects of feed withdrawal time from 0 to 16 hours on broilers live body weight after 8 weeks $(P<0.0001)$.

\subsection{Carcass yield}

The results showed variability in the dressing percentage or meat yield in broilers from all the feed withdrawal treatments. The percentages of meat yield were $80,86.4,78,82.9$ and $80.9 \%$ respectively. It appeared that birds on the 4 hours feed withdrawal had the highest meat yield and could be recommended as the best feed withdrawal treatment. The highest yield obtained with the 4 hours of feed withdrawal may be due to the lower live shrink or loss in live weight.

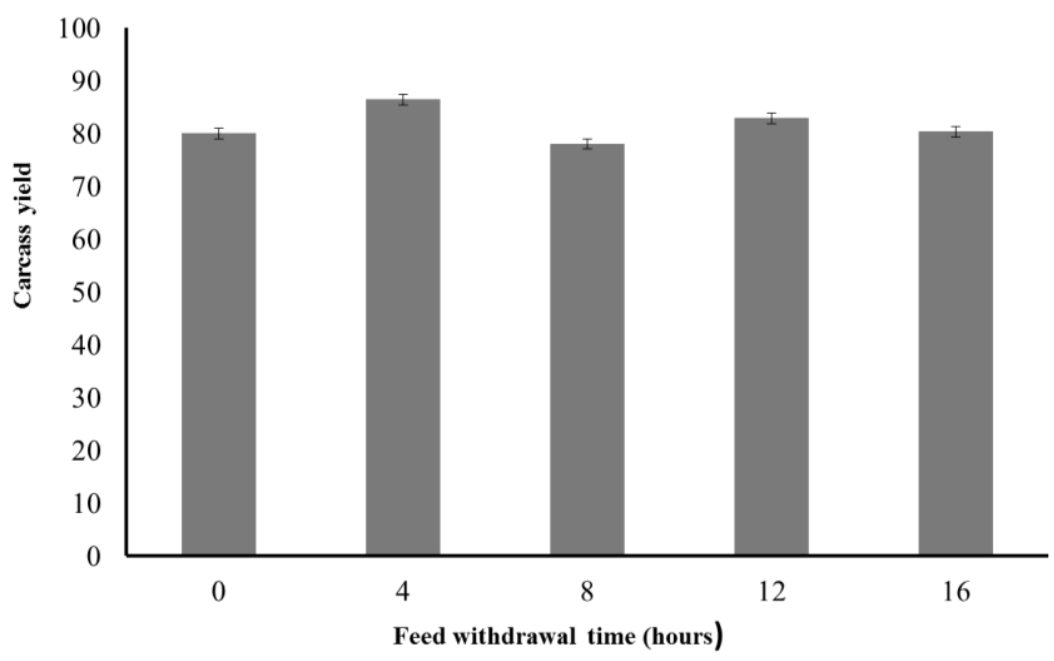

Fig2. Effects of feed withdrawal time from 0 hour to 16 hours on broiler carcass yield at 8 weeks. 
In the current study, a further increase in feed withdrawal time improved the yield but the differences in yield for birds on 8 hour, $12 \mathrm{~h}$ and $16 \mathrm{~h}$ of feed withdrawal time were not large. Bases on the performance of other parameters such as live body and weight gain, 8 hours feed withdrawal treatment appeared to be the optimum .Bilgili (2002) reported that optimum feed withdrawal time must be long enough to allow adequate gastrointestinal tract clearance, but also shortest possible to reduce live shrink. This variability implies that various factors are required to make statement on optimum feed withdrawal timing on broilers. Previous studies have recommended both 8 and 12 hours as best feed withdrawal timing (Northcutt 2001) but these have to be timed well to meet the processor and producers half way to avoid inconveniences as well as reduce impact on broiler yield following processing

\subsection{Intestinal integrity}

The weight of the intestines and crop were significantly different between the feed with withdrawal treatments. Also the average intestinal and crop weights (figure 4) for zero hour, four hours, eight hours, twelve hours and sixteen hours were recorded as $0.22 \mathrm{~kg}, 0.15 \mathrm{~kg}, 0.08 \mathrm{~kg}, 0.13 \mathrm{~kg}$ and $0.10 \mathrm{~kg}$ respectively. The dressed weight has been shown in figure 3 below. The pictures (a, b, c, d) in figure 3 below show the effects of feed withdrawal duration on the GIT. The first picture (a) is the intestine of the control birds which was full of faeces and we can see how tension is build up in it. Although the force build up in the intestine was not measured this could be a potential reason for accumulated gash out during automated processing.

In other words this will occupy larger space and can easily cut during slaughter causing contamination. The second picture (b) is the crop of birds after 16 hours feed withdrawal showing more water in it and this too can possibly cause contamination during evisceration. The third picture (c) is one showing weak intestines due to long feed withdrawal time. The picture (d) is showing some sloughing of the small intestine due to long feed withdrawal period. Sixteen hours of feed withdrawal caused a heavy sloughing of the intestines which means there is the possibility of intestinal breakage during processing. As Bilgili and Hess (1997) reported, the tensile strength of the small intestine decreases by $10 \%$ as the length of feed withdrawal increases above 14 hours. They also determined that the intestinal and crop weight as part of the digestive tract decreased in parallel with feed withdrawal duration.

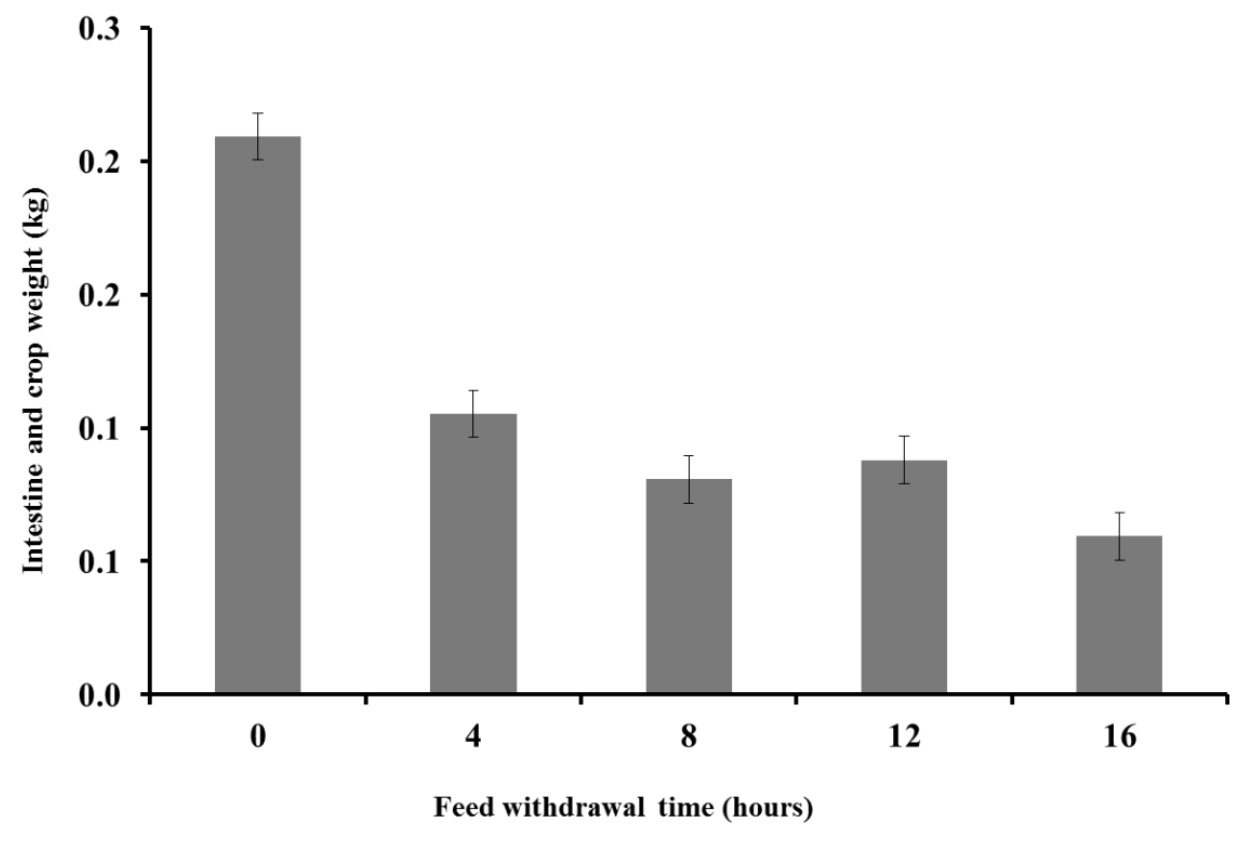

Fig4. Effects of feed withdrawal timing from 0 hour to 16 hours on broiler intestines and crop at 8 weeks.

Northcutt et al., (1997) confirmed that the best gastrointestinal clean-out was achieved when broilers were kept offfeed for 8-12 hours before slaughter. While this may not be a rule but just reference only, companies should understand that under practical conditions the period can vary below, between or even beyond these limits. According to Nuns (2005), the design and implementation of feed withdrawal programs differ from one country to another due to differences in the production practices, slaughter and inspection regulations. In this study the gastrointestinal tract was empty between the four to eight hours but the best time was the four hours feed withdrawal. 
a
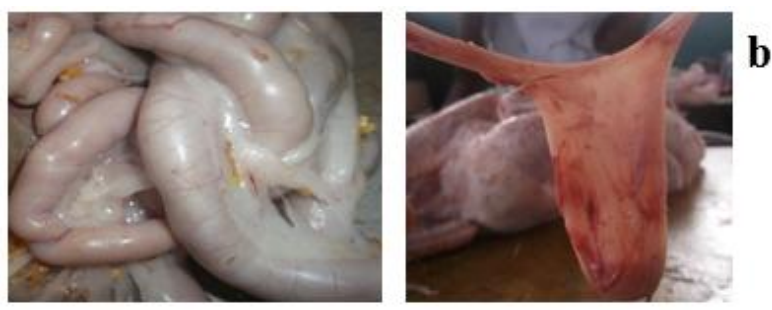

c
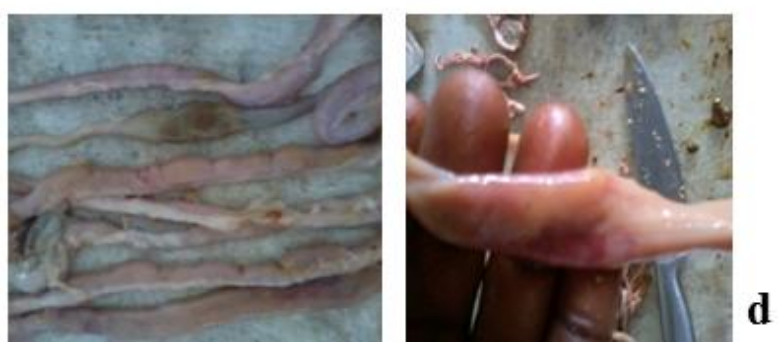

Fig3. Comparison of long feed withdrawal against no feed withdrawal on broiler intestinal and crop integrity: (a) full intestines following no feed withdrawal, (b) watering crop following 16 hours feed withdrawal, $(c)$ weak and fragile intestine disintegrating following feed withdrawal for 12 and 16 hours and (d) intestinal sloughing or breaking down of internal mucosa following long hours of feed withdrawal of 12 or 16 hours

\subsection{Dressed weight}

Figure5 shows that feed withdrawal timing had significant effects on the dressed weight after 56 days $(\mathrm{P}<0.001)$. Birds of the control ( 0 hourwhere there was no feed withdrawal) had the highest dressed weight, followed by birds in 4 hours feed withdrawal compared to all the feed withdrawal treatments $(8,12$, and 16 hours). However, Ahmad et al. (2006) observed significantly higher values in birds kept under feed withdrawal system for 8 hours.

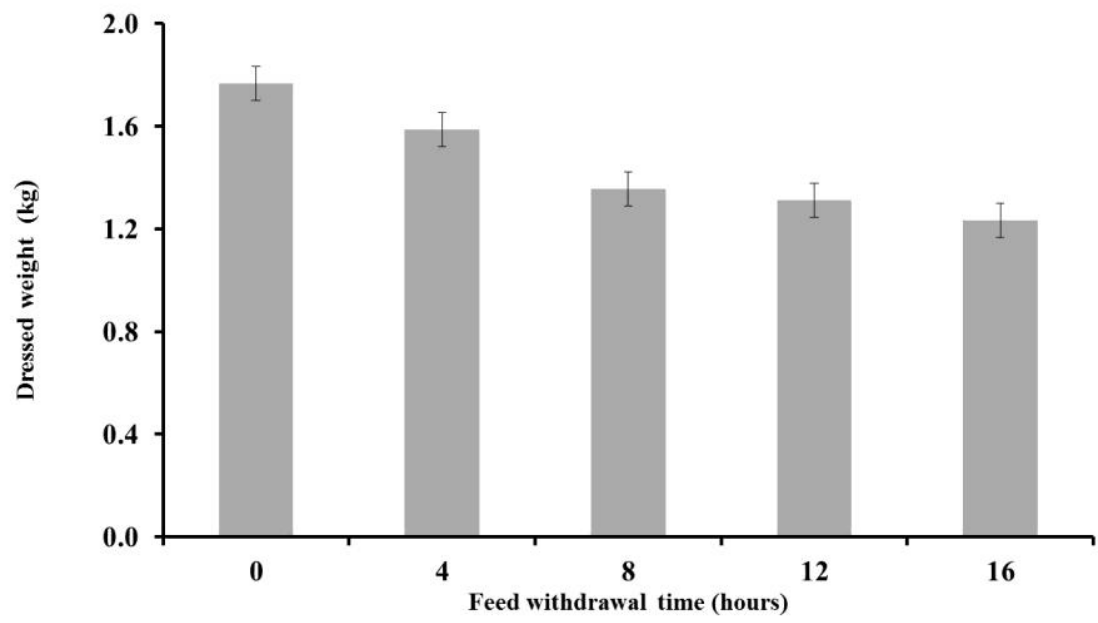

Fig5. Effects of feed withdrawal timing from 0 hour to 16 hours on the dressed weight of broilers at 8 weeks

\subsection{Feed conversion ratio}

Effects of feed withdrawal duration on feed conversion ratio (FCR) have been presented in figure 6 below. It was determined that feed withdrawal timing had significant effects on the feed conversion ratio after 56 days $(\mathrm{P}<0.001)$. Birds of the control (0 hour)where there was no feed withdrawal had the lowest feed conversion ratio, followed by birds in 4 hours feed withdrawal compared to all the feed withdrawal treatments $(8,12$, and 16 hours). But there was no significant difference between the 8,12 and 16 hours of feed withdrawal treatments. However, Turkyilmaz et al, 2006 observed a slight decrease in the FCR when the feed withdrawal time was increased but the reduction was not significant. 


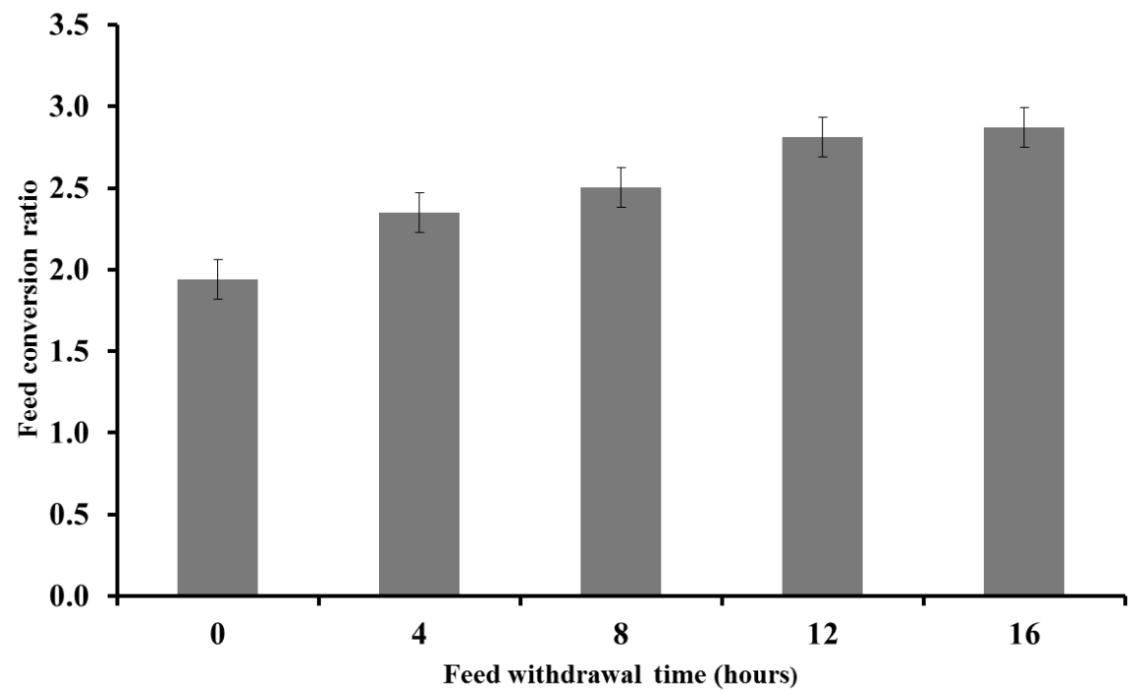

Fig6. Effects of feed withdrawal timing from 0 hour to 16 hours on feed conversion ratio of broilers at 8 weeks.

\section{CONCLUSION}

While feed withdrawal has it benefits, physical reduction in live body weight and dressed weight could pose a welfare concern in the long term. The 4 hours feed withdrawal could be considered sufficient to minimize the risk of carcass loss because it provided adequate time for gut clearanceand controlled yield losses. 12 and 16 hours could be more stressful on the birds than other treatments looking at some of the physical features of the tract.

\section{ACKNOWLEDGEMENT}

The authors would like to thank the management of Chick and Chickens Company Ltd some in-kind donation of chicks for this project and Darko farms and Co. Ltd for providing site and facilities for the first experiment. We also like to express our profound appreciation to staff and students of the Department of Animal Science who made this project a success especially Mr. Adama and Francis.

\section{REFERENCES}

[1] Abubakari, S. 2013. Development of Intensity-Duration-Frequency-Curves for Kumasi.MSc. Thesis. KNUST, Ghana.

[2] Ahmad, F., Mahmood, S., Zia-ur-Rehman, M., Ashraf, M., AlamM. and Asia, M. 2006.Effect of feeding management of thermoregulation, production performance and Immunological response of broilers during summer. International Journal of Agriculture and Biology volume 8 number 4 pages 1560-8530.

[3] AOAC International.2003. Official methods of analysis of AOAC International. 17th edition.2nd revision.Gaithersburg, MD, USA, Association of Analytical Communities.

[4] Baracho M.S., G.A Camargo, A.M.C Lima, J.F Mentem, D.J. Moura, J. Moreira, Naas I.A. 2006. Variables impacting poultry meat quality from production to pre-slaughter: a review. RevistaBrasileria de-sciElo B.

[5] Bilgili, S.F., and J.B. Hess. 1997. Tensile strength of broiler intestines as influenced by age and feed withdrawal. Journal Applied Poultry Research. 6:279-283.

[6] Bilgili, S.F.2002. Slaughter quality as influenced by feed withdrawal. World Poultry Science Journal 58: 123-130.

[7] Buhr, R.J., Northcutt, J.K., Lyon, C.E., Rowland, G.N. 1998. Influence of time off feed on broiler viscera weight, diameter, and shear. Poultry Science 77: 758-764.

[8] Crampton E. W. and Harris, L. E. 1996.Animal Nutrition. The used of fee

[9] dstuffs in the formation of livestock rations. 2nd Edition. W. H. Freeman and Co., San Francisco California USA page 36.

[10] Duke, G.E., M. Basha and Noll, S. 1997. Optimum duration of feed and water removal prior to processing in order to reduce the potential for faecal contamination in turkeys. Poultry Science 76: 516-522.

[11] Hamidu, J.A.2002. Comparison of three litter materials, wood shavings, rice husks and 50\% each of wood shavings and rice husk combined. BSc. Thesis.KNUST Kumasi, Ghana.

[12] Javadi, A. and S. Safarmashae. 2011. Microbial peofile of marketed broiler meat. Middle-East Journal of Scientific Research 9: 652-656. 
[13] Lyon, C. E., C. M. Papa and R. L. Wilson Jr. 1991.Effect of Feed Withdrawal on Yields, Muscle pH and Texture of Broiler Breast Meat. Poultry Science Volume 70(4):1020-1025

[14] May, J.D., and J.W. Deaton. 1989. Digestive tract clearance of broilers cooped or deprived of water. Poultry Science.68:627-630.

[15] Northcutt, J. K., M. E. Berang. J. A. Dickens, D. L. Fletcher and N. A. Cox 2003.Effect of broiler age, feed withdrawal and transportation on levels of coliforms campylobacter, Escherichia coli and salmonella on carcasses before and after immersion chilling. Poultry Science 82:169-173.

[16] Northcutt, J. K., S. I. Savage, and L. R. Vest. 1997. Relationship between feed withdrawal and viscera condition of broilers. Poultry Science. 76:410-414.

[17] Northcutt, J.K. (2001). Pre-slaughter factors affecting poultry meat quality, Chapter 2, pages 5-18. In: Sams, A.R. (2001) Poultry Meat Processing. C.R.C. Press. Boca Ration, Florida.334p.

[18] Nunes, F. 2005. Feed withdrawal to reduce carcass contamination. World Poultry Volume 21 No. 1.Pages 36-38.

[19] Orlic, D.M., Kapetanov, D. Potkonjak, and D. Stojanović. 2007. The influence of feed withdrawal and transportation on weight loss, mortality rate andcarcass quality in broilerchickens at slaughter.Scientific Veterinary Institute Volume 40:512518.

[20] Rigby, C. E. and J. R. Petit .1981.Effects of feed withdrawal on weight, faecal excretion and salmonella status of market age broiler chickens. Canadian journal comp. med 45: 363-365.

[21] Stan Savage 1998. Feed withdrawal: a practical look its effect on intestine emptying, contamination and yield. Pfizer Inc. C. Bennett. Animal Industry Branch, Manitoba Agriculture and Food.

[22] Summers, J.D. and Leeson, S. 1979. Comparison of feed withdrawal time and passage of gut contents in broiler chickens held in crates or litter pens. Canadian Journal of Animal Science, 59:63-66.

[23] Turkyilmaz, M. K., A. Nazligul, S. Turkyilmaz and E. Fidan. 2006. Effects of different feed withdrawals on the performance and faecal contamination of carcass in broiler chickens. International journal of poultry science 5: 975-978.

[24] UCD INSTITUTE OF FOOD AND HEALTH.Policy Seminar Series.Mapping food and health to the public policy landscape.www.ucd.ie/foodandhealth. Accessed on February, 14th 2014.

[25] Dr. Mansel W. G. (2008). Canadian Research, Institute for food Safety, University of Guelph. The Maple Leaf Foods Outbreak in Canada: learning to prevent future incidence.

[26] Wabeck, C.J. 1972. Feed and Water withdrawal time Relationship to processing yield and potential faecal contamination of Broilers. Poultry Science Volume 51 number 4 pages 1119-1121.

[27] Zuidhof, M. J., R. H. McGovern, B. L. Schneider, J. J. R. Feddes, F. E. Robinson and D. R. Korver. 2004. Effects of Feed Withdrawal Time on the Incidence of faecal spillage and contamination of broiler carcass at processing. Journal of Applied Poultry Research 13:171-177. 